\title{
Illicium use in Brazilian batfish Ogcocephalus vespertilio (Linnaeus, 1758) feeding behavior in nature and in captivity
}

\author{
Vivian Maria Pereira Alves ${ }^{1,2(0)}$, Ricardo Campos-da-Paz ${ }^{2}{ }^{\oplus}$, Marcelo Vianna $^{1,3, *(1)}$ \\ ${ }^{1}$ Universidade Federal do Rio de Janeiro, Departamento de Biologia Marinha, Laboratório de Biologia e Tecnologia Pesqueira (Av. \\ Carlos Chagas Filho, 373 - Cidade Universitária - 21941-902 - Rio de Janeiro - RJ - Brazil). \\ ${ }^{2}$ Universidade Federal do Estado do Rio de Janeiro, Instituto de Biociências, Departamento de Ecologia e Recursos Marinhos, \\ Laboratório de Ictiologia Neotropical (Av. Pasteur, 458/408 - Urca - 22290-240 - Rio de Janeiro - RJ - Brazil). \\ ${ }_{3}^{3}$ IMAM-AquaRio - Rio de Janeiro Aquarium Research Center (Praça Muhammad Ali - Via Binário do Porto, s/n - Gamboa - $20220-360$ - \\ Rio de Janeiro - RJ - Brazil). \\ * Corresponding author: mvianna@biologia.ufrj.br
}

The Lophiiformes order represents a group of eighteen families of marine fishes exhibiting an overall specialized morphology, including distinctive structures used in feeding mechanisms and predation strategies (Nelson et al., 2016). This includes the illicium, a modification of the first dorsalfin spine into a fishing pole, usually bearing a distal bilaterally symmetrical glandular structure known as a lure (esca). The illicium/lure structure attracts prey attention in a manner similar to a fishing apparatus, and the esca can be bioluminescent in deepsea species or release chemicals for this purpose (Bradbury, 1980; Nagareda and Shenker, 2009). When the illicium is retracted, the lure is sheltered in the illicium cavity between the mouth and the tip of the snout (Bradbury, 1980). The lophiiform genus Ogcocephalus Fisher, 1813 (Ogcocephalidae) currently includes 13 species known as batfishes, which inhabit tropical and subtropical waters, reaching up to $40 \mathrm{~cm}$ total length (TL), and presenting modified pectoral and pelvic fins for specialized substrate movement, allowing them to slowly "walk" on the bottom, swimming only short distances (Gibran \& Castro, 1999). Ogcocephalus vespertilio (Linnaeus, 1758), the Brazilian batfish, occurs from the mouth of the

Submitted on: 13-December-2020

Approved on: 19-January-2021

Editor: Rubens M. Lopes

ㅇ 2021 The authors. This is an open access article distributed under the terms of the Creative Commons license.
Amazon River, in northern Brazil, to the mouth of the La Plata River, in Argentina, and is common in shallow coastal waters (Bradbury, 1980). Studies concerning this species feeding behavior are scarce, but it is known that its diet is composed mainly of small crustaceans (Gibran and Castro, 1999).

Although $O$. vespertilio apparently uses its illicium to attract prey, this function is still questioned. Gibran and Castro (1999) observed this species behavior in the wild and did not confirm the use of the illicium in active predation (i.e. prey attraction). Nagareda and Shenker (2009), on the other hand, reported that the esca at the tip of the illicium in polka-dot batfish Ogocephalus cubrifrons Richardson, 1836 from Florida (USA) apparently secrete a chemical compound that generates an attraction responses in gastropods. In this context, the present contribution aims to provide additional information regarding $O$. vespertilio feeding behavior in both its natural environment and in captivity, as well as to verify illicium use by direct observations and filming.

Natural environmental observations (in situ) were performed on August 6, 2011, during a night dive, where an $O$. vespertilio individual was filmed at a depth of $34 \mathrm{~m}$, at the Parcel Manuel Luiz Marine State Park $\left(00^{\circ} 52^{\prime} \mathrm{S}, 44^{\circ} 16^{\prime} \mathrm{W}\right)$, a reef formation in Maranhão (Brazil), located $86.3 \mathrm{~km}$ from the coast (Rocha et al, 2001). The video focused on the feeding behavior of the species with an emphasis on illicium use. The observer and camera maintained a distance 
sufficient to not to interfere with the individual's foraging activity. Behavioral identification and description from the filming results followed the ad libitum method (Altmann, 1974).

Captivity observations were carried out using two O. vespertilio individuals at the Rio de Janeiro Marine Aquarium (AquaRio), in May 2018, in the morning during their feeding routine, when the Marine Aquarium is closed for visitation, eliminating possible public interference regarding food behavior. The studied tank (2,000 L capacity) contains gravel as substrate, as well as rocks and artificial algae, seeking to reproduce the species natural environment. The fish are fed live shrimp once a day, with sporadic offerings of Poecilidae specimens (Cyprinodonotiformes) and small fish pieces. Individual feeding identification and description behavior also followed the ad libitum method (Altmann, 1974). Observations were carried out twice a week for six days, with each observation lasting 30 minutes, totaling 180 minutes. The videos, both in the wild and in captivity, were analyzed at the Biology and Fisheries Technology Laboratory (BioTecPesca/UFRJ), Rio de Janeiro, Brazil.

During in situ foraging, two $O$. vespertilio locomotion modes were observed. First, displacement was slow, with the individual alternately using its pectoral and pelvic fins to slowly slide along the substrate. The second mode resembled a jump, with the individual using its pectoral fins to gain impulse, with the pelvic fins positioned ahead, finishing with a quick lunge. When stationary, the batfish used its cryptic coloration to camouflage in the sandy soil, apparently waiting for prey. In this situation, the individual remained supported on its pelvic and pectoral fins in contact with the sediment, and extended and retracted its illicium three times, exposing the lure (Fig. 1). Whenever illicium movement was carried out, a small crustacean located in front of the fish seemed attracted. When potential prey moved, the batfish detected and slowly approached them with the aid of its pelvic and pectoral fins, attacking in a single, quick, movement (Fig. 1). In one of the attacks, a crustacean was close; the batfish carefully projected the anterior part of its body, placed its mouth over the prey and ingested it by rapid jaw protraction. On another occasion, after an attack, the batfish seemingly ingested sediment from the sandy bottom, rapidly eliminating a dense cloud of particles through mouth and gill protraction, corroborating the behavior described by Gibran and Castro (1999), also similar to a recorded failed attack, in which the batfish ingested pieces of seaweed, expelling them immediately.

During the tank observations, the two assessed individuals remained stationary, not moving or swimming significant distances. One became more

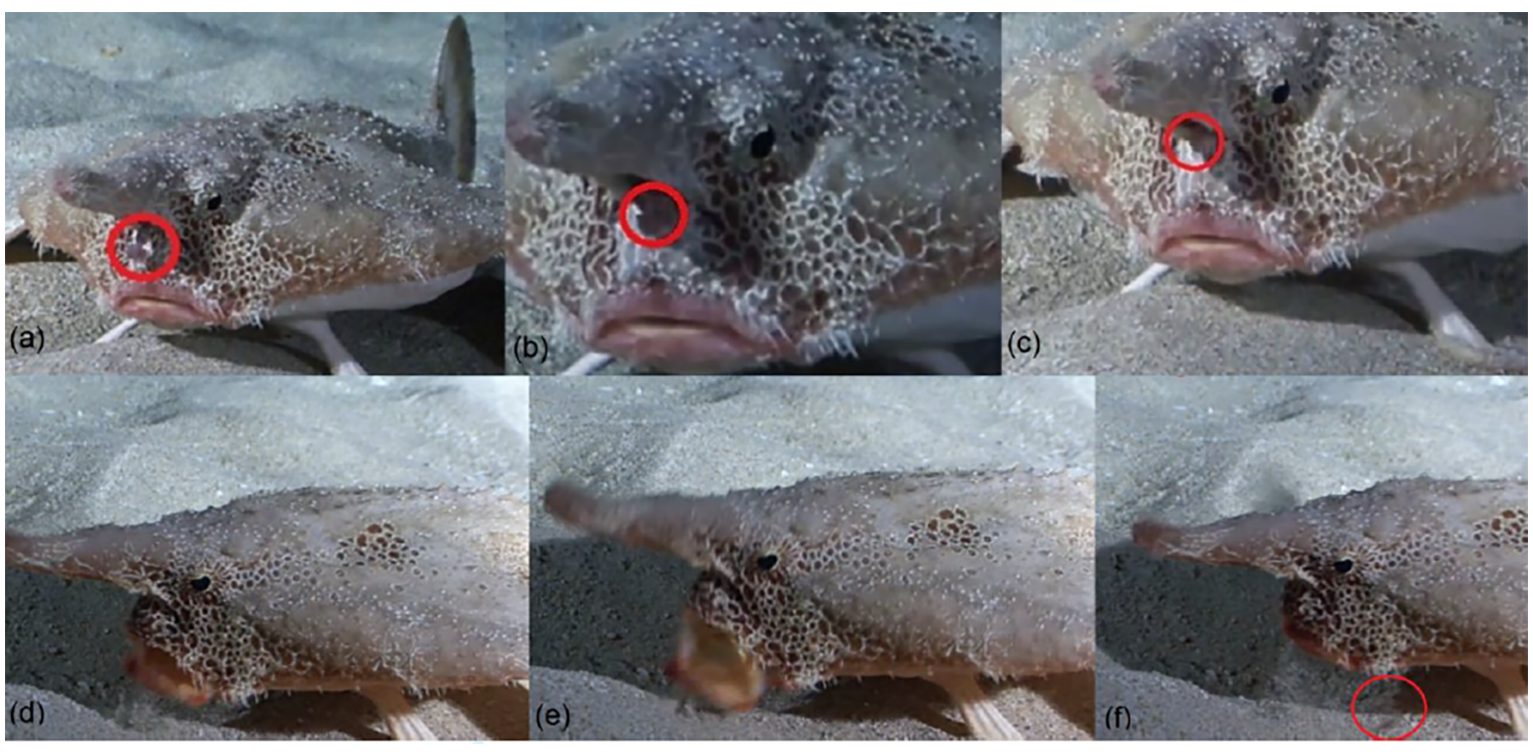

Figure 1. Sequence of photos of an Ogcocephalus vespertilio individual in nature: (a) stationary, exhibiting maximum illicium protraction; (b) partial illicium retraction; (c) full illicium retraction; (d) initial mouth protraction; (e) maximum mouth protraction; (f) full mouth retraction after a successful attack on a small crustacean. 
active than the other after feeding. When immobile, the individuals remained supported on the substrate on their pectoral and pelvic fins, identical to their natural environment behavior. When food was offered, the most active individual detected and tracked its prey, hidden in the side of the tank, and swam towards it. Caudal fin propulsion, alongside pectoral and pelvic fins movements, led to a quick attack, ending with prey capture.

During food offering moments, individuals apparently visually detected the prey, maintaining the front of their body almost erect towards the top of the aquarium, remaining static until tracking their prey. At times, individuals swam slowly near the bottom for short distances, chasing shrimp, often unsuccessfully. As in nature, two types of movement were observed during foraging. In the first, the fish used their pectoral and pelvic fins to slowly slide across the substrate, followed by an attack, while the second resembled a leap, in which the caudal, anal, and pectoral fins provided impulse, while the pelvic fins were positioned ahead. Breder (1949) observed this same behavior in captive Ogcocephalus radiatus Mitchill, 1818. When prey swam near the $O$. radiatus individual in the water column, the batfish attacked, sometimes unsuccessfully, in a fast lunge. If the prey was at the bottom of the enclosure, the batfish moved carefully, very slowly positioning the front of its body in order to move its mouth over the prey, quickly swallowing it with its protractile mouth. After several unsuccessful attacks, the individuals ingested substrate fragments and, as in the wild, immediately eliminated a cloud of particles through the gills and mouth. One of the individuals was observed moving its illicium on two occasions in the tank. In the first, the illicium was projected and retracted, exhibiting the lure only when food was offered, while the second frantically moved its illicium back and forth to the left and right before food was released into the tank. When food was, in fact, offered, the individual quickly retracted its illicium, remaining still and apparently using its eyes to track the prey. Visual stimulation by illicium movement for prey attraction was not observed.

Both the natural environment and captivity findings indicate that $O$. vespertilio exhibits a steady behavior, moving short distances and occupying the same site for long periods of time. This corroborates
Gibran and Castro (1999), who assessed this species in southeastern Brazil, and observed them to be immobile, hidden in cracks and between rocks, or camouflaged on the sandy bottom. Substrate movement near potential prey has been described by several authors (Breder, 1949; Lundsten et al., 2012; Barret et al., 2016). Breder (1949), when observing captive $O$. radiatus, who described its movements as jumping, comparable to a frog or rabbit, while the other movement was compared to a "trot". The same movements were recorded in the present study in $O$. vespertilio, which, despite moving ("walking") most of the time in a somewhat elegant way, alternating paired fins for substrate sliding, also displayed movements similar to jumps, both in situ and in captivity. According to Barret et al. (2106), batfishes also swim in search of prey, even though they are slow and uncoordinated swimmers. Gibran and Castro (1999) reported O. vespertilio as swimming 50 $\mathrm{cm}$ above the bottom in a straight line, propelled by the caudal fin, but indicated that this is an apparently rare behavior. Other lophiiforms, such as Lophius piscatorius Linnaeus, 1758 (Lophiidae), also move in a similar manner to "walking", using their pectoral and pelvic fins to travel supported on the sediment bottom (Laurenson et al., 2004).

Batfishes are recognized for their close association to the substrate, as they spend their life in contact with, or near, the bottom, and are a benthic invertebrate predator (Gibran and Castro, 1999; Barret et al., 2016). According to Gibran and Castro (1999), they are opportunistic sit-and-wait predators, waiting for prey in an immobile and camouflaged stance, moving only short distances. Therefore, the strategy of attracting and catching prey using the illicium as a fishing apparatus should be relevant for this type of behavior.

Both in situ and in captivity observations have shown that $O$. vespertilio constantly moves its illicium. This is mostly observed in the species natural environment, in which visual stimulation aiming to attract benthic invertebrates is successfully practiced. In addition, the video recording obtained herein seems to indicate that the illicium may actually secrete a chemical compound, corroborating studies that claim that the terminal lure can release chemical attractants that attract prey to $O$. vespertilio's lunging range (Nagareda and Shenker, 2009). Thus, this 
species may be able to employ preying strategies by using chemical stimulants to attract prey while using the illicium to visually attract prey, ending with an attack.

Currently available research on Ogcocephalidae (as well as on the Lophiidae and Antennariidae, Lophiiformes families) indicate relatively poor knowledge on their dietary behavior and the use of the illicium in prey capture behavior. The use of the illicium as a fishing apparatus to visually stimulate prey is a strategy applied by most Lophiiformes (Armstrong et al., 1996), such as L. piscatorius, where in situ observations report that this species only moves its illicium when the prey is positioned ahead of the individual. When the potential prey is located in an unsuitable attack position, i.e. behind the fish, this attraction strategy is not activated (Laureson et al., 2004). When studying the Chaunacops coloratus (Garman, 1899) (Chaunacidae) in the Pacific, Lundsten et al. (2012) observed that this species exhibited its illicium and lure in a fishing position for about 25 seconds, followed by illicium retraction into the illicium cavity. Brauwer and Hobbs (2016) demonstrated that the lure in the Antennarius striatus (Shawn, 1794) (Antenariidae) displays the same coloration and size as their preferred prey in its surroundings, and is used as a prey attractive. However, the attraction practice is not always activated for a successful attack (Nagareda and Shenker, 2009). Batfishes may also employ prey pursuit behavior, since they are active at the same times as their prey, which include polychaetes, crustaceans and echinoderms (Gibran and Castro, 1999; Nagareda and Shenker, 2009). In addition, many of their potential prey display restricted locomotion capabilities (Nagareda and Shenker, 2009), so attraction behavior is not heavily applied in these cases (Nagareda and Shenker, 2009; Mahapatro et al., 2018).

Apparently the illicium/lure (esca) apparatus can act both in visual and chemical attraction (Bradbury, 1980; Barret et al., 2016). Although O. vespertlio individuals were seen moving their illicia while in captivity, visual stimulation was not apparently applied for prey attraction in those situations. However, in the natural environment, the seduction practice was effective, ending in successful attacks. We believe that optional illicium use can be explained by prey availability. Considering that food availability is high in captivity, comprising different prey items than those usually found in the wild offered daily, in adequate amounts and at regular times, illicium use to obtain food is less necessary. The observed illicium use behavior during food offering may be the result of conditioning and the natural foraging practice of the species. However, Breder (1949), when observing O. radiatus in captivity, pointed out that illicium movement only occurred when small fish were placed in the aquarium and when the batfish did not visualize its prey, suggesting illicium functionality as a fishing tool. In this sense, we agree with Bradbury (1967) and Combs (1973), who suggest that the illicium lure can secrete chemical attraction and is not exclusive for visual attraction. New studies on the feeding behavior of $O$. vespertilio should aid in understanding preying strategies, since the illicium is obviously functional but its use is apparently optional, according to the available prey supply and quality. In this sense, does the illicium actually secrete chemical stimulants in $O$. vespertilio? Also, is it specific to a particular group of species? Further studies are required to clarify this exquisite form of prey capture in this species.

\section{ACKNOWLEDGMENTS}

The authors would like to thank the National Council for Scientific and Technological Development (CNPq) for financial support for Marcelo Vianna, seed grants from AquaRio, and Fabio Borges Pereira for the underwater filming in the natural environment.

\section{AUTHOR CONTRIBUTIONS}

V.M.P.A.: Investigation; Writing - original draft; Writing - review \& editing.

R.C.P.: Supervision; Writing - review \& editing.

M.V.: Conceptualization; Validation; Writing - review \& editing; Funding acquisition.

\section{REFERENCES}

ALTMANN, J. 1974. Observational study of behavior: sampling methods. Behaviour, 49(3-4), 227-267.

ARMSTRONG, M. P., MUSICK, J. A. \& COLVOCORESSES, J. A. 1996. Food and ontogenetic shifts in feeding of the goosefish, Lophius Americanus. Journal of Northwest Atlantic Fishery Science, 18, 99-89.

BARRETT, L. C., MONTOYA, P. Z., TORRES, L. A. \& FOSTER IV, J. W. 2016. The natural history and husbandry of the walking batfishes (Lophiiformes: Ogcocephalidae). Drum and Croaker, 47, 7-40.

BRADBURY, M.G. 1980. A revision of the fish genus Ogcocephalus with descriptions of new species from the western Atlantic Ocean (Ogcocephalidae: Lophiiformes). Proceedings of the California Academy of Sciences, 42(4), 229-285. 
BRAUWER, M. \& HOBBS, J. P. A. 2016. Stars and stripes: biofluorescent lures in the striated frogfish indicate role in aggressive mimicry. Coral Reefs, 35(4), 1171-1171.

BREDER, C. M. J. 1949. On the relationship of social behavior to pigmentation in tropical shore fishes. American Museum of Natural History, 94(2), 83-106.

GIBRAN, F. Z. \& CASTRO R. M. C. 1999. Activity, feeding behaviour and diet of Ogcocephalus vespertilio in southern West Atlantic. Journal of Fish Biology, 55(3), 588-595.

LAURENSON, C. H., HUDSON, I. R., JONES, D. O. B. \& PRIEDE I. G. 2004. Deep water observations of Lophius piscatorius in the north eastern Atlantic Ocean by means of a remotely operated vehicle. Journal of Fish Biology, 65(4), 947-960.

LUNDSTEN, L., JOHNSON, S. B., CAILLIET, G. M., DEVOGELAERE, A. P. \& CLAGUE, D. A. 2012. Morphological, molecular, and in situ behavioral observations of the rare deep-sea anglerfish Chaunacops coloratus (Garman, 1899), order Lophiiformes, in the eastern North Pacific. Deep Sea Research Part I: Oceanographic Research Papers, 68, 46-53.
MAHAPATRO, D., PANIGRAHY, R. C., PANDA, S., KARNA S. K. MISHRA, R. K., MISHRA, S. S. \& MOHANTY, S. K. 2018. New distributional record of Halieutea Indica (Lophiiformes: Ogcocephalidae) from Chilika Lagoon, India. Indian Journal of Geo Marine Sciences, 47(8), 1594-1600.

NAGAREDA, B. H. \& SHENKER, J. M. 2008. Dietary analysis of batfishes (Lophiiformes: Ogcocephalidae) in the Gulf of Mexico. Gulf of Mexico Science, 26(1), 28-35.

NAGAREDA, B. H. \& SHENKER, J. M. 2009. Evidence for chemical luring in the polkadot batfish Ogcocephalus cubifrons (Teleostei: Lophiiformes: Ogcocephalidae). Florida Scientist 72(1), 11-17.

NELSON, J. S., GRANDE T. C. \& WILSON M. V. 2016. Fishes of the world. $5^{\text {th }}$ ed. New Jersey: John Wiley and Sons.

ROCHA, L. A. \& ROSA, I. L. 2001. Baseline assessment of reef fish assemblages of Parcel Manuel Luiz Marine State Park, Maranhão, north-east Brazil. Journal of Fish Biology, 58(4), 985-998. 